\title{
Tri-iodothyronine treatment differently affects liver metabolic response and oxidative stress in sedentary and trained rats
}

\author{
Paola Venditti*, Angela Bari*, Lisa Di Stefano* and Sergio Di Meo* \\ Dipartimento delle Scienze Biologiche, Sezione di Fisiologia, Università di Napoli 'Federico II', Via Mezzocannone 8, I-80134 Napoli, Italy \\ (Correspondence should be addressed to P Venditti; Email: venditti@unina.it) \\ *(All authors contributed equally to this work)
}

\begin{abstract}
We investigated whether swim training modifies the effects of tri-iodothyronine $\left(\mathrm{T}_{3}\right)$ treatment on the metabolic response and oxidative damage of rat liver. Respiratory capacities, oxidative damage, levels of antioxidants, and susceptibility to oxidative challenge of liver homogenates were determined. Mitochondrial respiratory capacities, rates of $\mathrm{H}_{2} \mathrm{O}_{2}$ release, and oxidative damage were also evaluated. Training modified most of the measured parameters in both thyroid states, although the extent of changes was higher in hyperthyroid preparations. $T_{3}$ treatment enhanced homogenate respiratory capacity, which was further enhanced by training despite the decrease in mitochondrial respiratory capacity. Hormonal treatment also induced liver oxidative damage and glutathione depletion, and increased tissue susceptibility to oxidative challenge. These effects were lower in trained animals. The extensive oxidative

damage found in liver homogenates from hyperthyroid sedentary rats was due to low tissue antioxidant protection and high mitochondrial $\mathrm{H}_{2} \mathrm{O}_{2}$ production rate, which were increased and decreased respectively by animal training. The training effect on $\mathrm{H}_{2} \mathrm{O}_{2}$ production was associated with lower oxidative damage and susceptibility to $\mathrm{Ca}^{2+}$-induced swelling of mitochondria. Measurements with respiratory inhibitors indicated that the differences in $\mathrm{H}_{2} \mathrm{O}_{2}$ release in hyperthyroid groups were due to differences in mitochondrial content of autoxidizable electron carrier located at Complex III. We conclude that moderate training is able to reduce hyperthyroid state-linked cellular and subcellular oxidative damage in liver increasing its antioxidant defenses and decreasing the mitochondrial generation of reactive oxygen species.

Journal of Endocrinology (2008) 197, 65-74
\end{abstract}

\section{Introduction}

It is long known that in vertebrates that experimentally induced hyperthyroidism leads to accelerated basal metabolic rate and oxygen consumption in several tissues (Schwartz \& Oppenheimer 1978). It is also well established that the increased respiratory capacity displayed from rat tissues following prolonged thyroid hormone treatment is associated with oxidative stress, as documented by the high levels of oxidative damage indicators (Videla 2000, Venditti \& Di Meo 2006). Accumulating evidence has demonstrated that in the liver such effects are primarily due to increased tissue content of mitochondrial respiratory chain components (Brand \& Murphy 1987), including autoxidizable electron carriers (Venditti et al. 2003). This increase enhances tetravalent and univalent oxygen reduction, leading to higher oxygen consumption and reactive oxygen species (ROS) production respectively (Fernández \& Videla 1993, Venditti et al. 2003).

Studies on the effects of tri-iodothyronine $\left(\mathrm{T}_{3}\right)$ treatment on the antioxidant defense system of rat liver have shown that the changes in both the activities of antioxidant enzymes and the levels of low molecular weight scavengers are unbalanced and often opposite, although the whole antioxidant capacity significantly decreases in hyperthyroid state (Videla 2000, Venditti \& Di Meo 2006). This decrease is associated with a higher susceptibility of hepatic tissue to oxidative challenge both in vitro (Venditti et al. 1997, 1999a) and in vivo (Videla et al. 1995, Troncoso et al. 1997). Interestingly, $T_{3}$ effects appear to be strongly dependent on treatment duration. Indeed, ischemia-reperfusion injury, which is exacerbated by a 2-day $\mathrm{T}_{3}$ treatment (Troncoso et al. 1997), is reduced by a single $T_{3}$ dose (Fernández et al. 2007).

Hyperthyroid state-linked liver oxidative damage can be attenuated by strengthening antioxidant status, as demonstrated by the observation that the administration of vitamin $\mathrm{E}$ (Venditti et al. 1999a) and caffeic acid phenylethyl ester (Mohamadin et al. 2007) protects against lipid peroxidation in hyperthyroid liver.

Some studies indicate that antioxidant administration and moderate physical training can have similar protective effects in conditions leading to increased free radical production. For example, the appearance of signs of increased free radical generation induced by acute swimming was prevented in rat liver by both vitamin $\mathrm{E}$ administration (Brady et al. 1979) and training (Venditti \& Di Meo 1996). The training effect on liver was associated with an increase in tissue whole antioxidant 
defenses (Venditti \& Di Meo 1996). However, it is not possible to exclude that, like in rat skeletal muscle (Venditti et al. 1999b, Servais et al. 2003), a reduced free radical activity contributes to delayed peroxidative reactions in the hepatic tissue.

To shed some light on this matter, we evaluated the effects of physical training on respiratory capacity and oxidative damage of liver homogenates from euthyroid and hyperthyroid rats. Moreover, because mitochondria are a possible target of ROS, respiratory capacity and oxidative damage of mitochondrial preparations were also evaluated. Markers of lipid and protein damage were related with scavenger levels and susceptibility to oxidants of liver homogenates and with mitochondrial $\mathrm{H}_{2} \mathrm{O}_{2}$ production rates.

\section{Materials and Methods}

\section{Materials}

All chemicals used (Sigma Chimica) were of the highest grades available. The response to oxidative stress was determined using reagents and instrumentation of the commercially available Amerlite System (Ortho-Clinical Diagnostics, Milano, Italy).

Serum levels of free $\mathrm{T}_{3}\left(\mathrm{FT}_{3}\right)$ and thyroxine $\left(\mathrm{FT}_{4}\right)$ were determined using commercial RIA kits (DiaSorin, Salluggia, Italy).

\section{Animals}

Male Wistar rats (50 days old), supplied by Nossan (Correzzana, Italy) at day 45 of age, were randomly divided into sedentary and trained animals. Swimming, used as the exercise for the trained rats, was administered 5 days per week for 10 weeks. Our program provided initially brief swimming periods and their gradual lengthening to both facilitate the learning process and reduce the stress reaction. Therefore, in the first week, the rats were made to swim for 15 min daily to familiarize them with the water immersion. In the second week, the training session lasted $50 \mathrm{~min}$ and from the third to the tenth week the rats swam for $60 \mathrm{~min}$ a day. Swimming was performed in a plastic container that was $100 \mathrm{~cm}$ high, filled with water maintained at $35{ }^{\circ} \mathrm{C}$ to a depth of $55 \mathrm{~cm}$. Untrained animals were kept in a small chamber holding about $3 \mathrm{~cm}$ water maintained at $35^{\circ} \mathrm{C}$.

Ten days before the end of the training program half of sedentary and trained rats were made hyperthyroid by the treatment with daily i.p. injections of $\mathrm{T}_{3}(10 \mu \mathrm{g} / 100 \mathrm{~g}$ body weight). Thus, there were four groups of rats: euthyroid sedentary (ES), euthyroid trained (ET), hyperthyroid sedentary (HS), and hyperthyroid trained (HT).

All the rats were subjected to the same conditions (one per cage, constant artificial circadian cycle of 12-h light:12-h darkness, and $50 \pm 10 \%$ relative humidity), and fed the same diet, a commercial rat chow purchased from Nossan, and water on an ad libitum basis.
The treatment of animals in these experiments was in accordance with the guidelines set forth by the University's Animal Care Review Committee.

\section{Liver homogenate preparation}

Twenty-four hours following the end of the training program, at about 120 days of age, all animals were killed by decapitation while under ether anesthesia. Arterial blood samples were collected and later analyzed to determine the plasma levels of $\mathrm{FT}_{3}$ and $\mathrm{FT}_{4}$. The livers were rapidly excised and placed into ice-cold homogenization medium (HM; $220 \mathrm{mM}$ mannitol, $70 \mathrm{mM}$ sucrose, $1 \mathrm{mM}$ EDTA, $0 \cdot 1 \%$ fatty acid-free albumin,

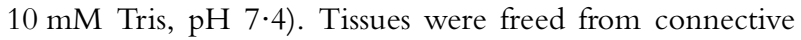
tissue and were weighed, finely minced, and washed with HM. Finally, tissue fragments were gently homogenized $(20 \% \mathrm{w} / \mathrm{v})$ in the same solution using a glass Potter-Elvehjem homogenizer set at a standard velocity (500 r.p.m.) for $1 \mathrm{~min}$. Aliquots of homogenates were used for analytical procedures and preparation of mitochondrial fractions.

\section{Preparation of mitochondria}

The homogenates, diluted 1:1 with HM, were freed of debris and nuclei by centrifugation at $500 \mathrm{~g}$ for $10 \mathrm{~min}$ at $4{ }^{\circ} \mathrm{C}$. The resulting supernatants were centrifuged at $10000 \mathrm{~g}$ for $10 \mathrm{~min}$. The mitochondrial pellets were resuspended in washing buffer (WB; $220 \mathrm{mM}$ mannitol, $70 \mathrm{mM}$ sucrose, $1 \mathrm{mM}$ EGTA, $20 \mathrm{mM}$ Tris, $\mathrm{pH} 7 \cdot 4$ ) and centrifuged at the same sedimentation velocity. Mitochondrial preparations were washed in this manner twice before final suspension in WB. Mitochondrial protein was measured by the biuret method (Gornall et al. 1949).

\section{Analytical procedures}

Cytochrome oxidase (COX) activity was determined by the procedure of Barré et al. (1987) using liver homogenates and mitochondrial suspensions diluted with modified ChappelPerry medium so that the preparations contained per $\mathrm{ml}$ either $100 \mathrm{mg}$ tissue or $0.2 \mathrm{mg}$ mitochondrial proteins.

Oxygen consumption of homogenates and mitochondria was monitored at $30^{\circ} \mathrm{C}$ by a Hansatech respirometer in $1.6 \mathrm{ml}$ incubation medium $(145 \mathrm{mM} \mathrm{KCl}, 30 \mathrm{mM}$ HEPES, $5 \mathrm{mM}$ $\mathrm{KH}_{2} \mathrm{PO}_{4}, 3 \mathrm{mM} \mathrm{MgCl}, 0 \cdot 1 \mathrm{mM}$ EGTA, pH 7-4) with $50 \mu \mathrm{l}$ homogenate or $0.25 \mathrm{mg}$ mitochondria per $\mathrm{ml}$ and succinate $(10 \mathrm{mM})$, plus $5 \mu \mathrm{M}$ rotenone (Rot), or pyruvate/malate $(10 / 2.5 \mathrm{mM})$ as substrates, in the absence (State 4$)$ and in the presence (State 3 ) of $500 \mu \mathrm{M}$ ADP.

The extent of the peroxidative processes in liver homogenates and mitochondrial preparations was determined by measuring the level of lipid hydroperoxides (HPs) according to Heath \& Tappel (1976). Determination of protein oxidative damage was performed measuring proteinbound carbonyl levels by the procedure of Reznick \& Packer (1994) for homogenates and by the modified procedure of Schild et al. (1997) for mitochondria. 
Glutathione peroxidase (GPX) activity was assayed at $37{ }^{\circ} \mathrm{C}$ according to Flohé \& Günzler (1984) with $\mathrm{H}_{2} \mathrm{O}_{2}$ as substrate. Glutathione reductase (GR) activity was measured at $30{ }^{\circ} \mathrm{C}$ according to Carlberg \& Mannervik (1985).

Ubiquinols $\left(\mathrm{CoQH}_{2}\right)$ from $0.5 \mathrm{ml}$ of $10 \%$ homogenate were oxidized to ubiquinones (CoQs) with $0.5 \mathrm{ml}$ of $2 \%$ $\mathrm{FeCl}_{3}$ and $2.0 \mathrm{ml}$ ethanol. The content of CoQs was then determined according to Lang et al. (1986). Vitamin E content was determined using the HPLC procedure of Lang et al. (1986). Reduced glutathione (GSH) concentration was measured as described by Griffith (1980).

The rate of mitochondrial $\mathrm{H}_{2} \mathrm{O}_{2}$ release was measured at $30{ }^{\circ} \mathrm{C}$ following the increase in fluorescence (excitation at $320 \mathrm{~nm}$, emission at $400 \mathrm{~nm}$ ) due to oxidation of $p$-hydroxyphenylacetate (PHPA) by $\mathrm{H}_{2} \mathrm{O}_{2}$ in the presence of horseradish peroxidase (HRP; Hyslop \& Sklar 1984) in a computercontrolled Jasko fluorometer equipped with a thermostatically controlled cell-holder. The reaction mixture consisted of $0 \cdot 1 \mathrm{mg} / \mathrm{ml}$ mitochondrial proteins, $6 \mathrm{U} / \mathrm{ml} \mathrm{HRP,} 200 \mu \mathrm{g} / \mathrm{ml}$ $\mathrm{PHPA}$, and $10 \mathrm{mM}$ succinate, plus $5 \mu \mathrm{M}$ rotenone, or $10 \mathrm{mM}$ pyruvate $/ 2.5 \mathrm{mM}$ malate added at the end to start the reaction in a medium containing $145 \mathrm{mM} \mathrm{KCl}, 30 \mathrm{mM}$ HEPES, $5 \mathrm{mM}$ $\mathrm{KH}_{2} \mathrm{PO}_{4}, 3 \mathrm{mM} \mathrm{MgCl} 2,0 \cdot 1 \mathrm{mM}$ EGTA, $\mathrm{pH} 7 \cdot 4$. Measurements with the different substrates in the presence of $500 \mu \mathrm{M}$ ADP were also performed. Furthermore, the effects of two respiratory inhibitors were investigated: rotenone, which blocks the transfer of electrons from Complex I to ubiquinone (Palmer et al. 1968), and antimycin A (AA), which interrupts electron transfer within the ubiquinone-cytochrome $b$ site of Complex III (Turrens et al. 1985). Inhibitor concentrations (5 $\mu \mathrm{M}$ Rot, $10 \mu \mathrm{M}$ AA) that do not interfere with the detection PHPA-HRP system were used (Venditti et al. 2003).

Capacity to remove $\mathrm{H}_{2} \mathrm{O}_{2}$ was determined by comparing the ability of mitochondrial samples to reduce $\mathrm{H}_{2} \mathrm{O}_{2}$-linked fluorescent emission with that of desferrioxamine solutions (Venditti et al. 2001). Thus, the capacity of mitochondrial samples to remove $\mathrm{H}_{2} \mathrm{O}_{2}$ was expressed as equivalent desferrioxamine concentration.

Response to oxidative challenge was determined as previously described (Venditti et al. 1999c). Briefly, the samples of $10 \%(\mathrm{w} / \mathrm{v})$ homogenates were obtained by diluting the $20 \%$ homogenates with equal volumes of $0 \cdot 2 \%$ Lubrol in $15 \mathrm{mM}$ Tris, $\mathrm{pH} 8 \cdot 5$. Several dilutions of samples up to a tissue concentration of $0.002 \%$ were prepared in $15 \mathrm{mM}$ Tris $(\mathrm{pH}$ $8 \cdot 5)$. The assays were performed in microtiter plates. Enhanced chemiluminescence reactions were initiated by addition of $250 \mu \mathrm{l}$ of the reaction mixture to $25 \mu \mathrm{l}$ of the samples. The reaction mixture was obtained by mixing the solutions containing substrate in excess and signal generating reagents respectively in buffer at $\mathrm{pH} 8.6$ (Vitros Signal Reagent). The plates were incubated at $37^{\circ} \mathrm{C}$ for $30 \mathrm{~s}$ under continuous shaking and then transferred to a luminescence analyzer (Amerlite Analyzer). The emission values were fitted to doseresponse curves using the statistical facilities of the Fig.P graphic program (Biosoft, Cambridge, UK).
Mitochondrial swelling was spectrophotometrically measured by determining the apparent absorbance at $540 \mathrm{~nm}$ in a medium containing $125 \mathrm{mM}$ sucrose, $65 \mathrm{mM}$ $\mathrm{KCl}, 10 \mathrm{mM}$ HEPES, $\mathrm{pH} 7 \cdot 2,2 \mathrm{mM}$ succinate, $4 \mu \mathrm{M}$ rotenone, $0.3 \mathrm{mg}$ mitochondrial protein per $\mathrm{ml}$ of reaction mixture, $100 \mu \mathrm{M} \mathrm{Ca}^{2+}$, and $50 \mathrm{mM}$ EGTA or $100 \mu \mathrm{M}$ cyclosporin A (CSA) where indicated.

Mitochondrial membrane potential $(\Delta \Psi)$ was estimated through the fluorescence changes of safranine $(8 \mu \mathrm{M})$ recorded on the Jasko fluorometer (excitation wavelength $495 \mathrm{~nm}$, emission wavelength $586 \mathrm{~nm}$ ) in a medium containing $125 \mathrm{mM}$ sucrose, $65 \mathrm{mM} \mathrm{KCl}, 10 \mathrm{mM}$ HEPES, pH 7.2, $2 \mathrm{mM}$ succinate, $6 \mu \mathrm{M}$ rotenone, $0.3 \mathrm{mg}$ mitochondrial protein per $\mathrm{ml}$ of reaction mixture, $100 \mu \mathrm{M} \mathrm{Ca}^{2+} . \Delta \Psi$ was calculated according to Åkerman \& Wikström (1976) using a calibration curve obtained incubating mitochondria in a medium containing $200 \mathrm{mM}$ sucrose, $10 \mathrm{mM}$ HEPES, $\mathrm{pH}$ $7 \cdot 2,6 \mu \mathrm{M}$ rotenone, $0 \cdot 38 \mathrm{EDTA}, 8 \mu \mathrm{M}$ safranine, $38 \cdot 5 \mathrm{ng} / \mathrm{ml}$ valinomycin, and $\mathrm{KCl}$ at concentrations from 0 to $0.96 \mathrm{mM}$.

\section{Statistical analysis}

The data obtained in eight different experiments are expressed as means \pm S.E.M. Data were analyzed with a two-way ANOVA method. When a significant $F$ ratio was found, the Student-Newman-Keuls multiple range test was used to determine the statistical significance between means. The effects of respiratory inhibitors in the same group were statistically analyzed with the Student's $t$-test. Probability values $(P)<0.05$ were considered significant.

\section{Results}

The animal thyroid state was documented by their heart mass/body mass ratio and plasma levels of $\mathrm{FT}_{3}$ and $\mathrm{FT}_{4}$. Heart mass/body mass ratios were $2 \cdot 25 \pm 0 \cdot 04,2 \cdot 95 \pm 0 \cdot 05,3 \cdot 15 \pm$ $0 \cdot 07$, and $3 \cdot 30 \pm 0 \cdot 12$ in ES, ET, HS, and HT rats respectively. They were significantly $(P<0 \cdot 05)$ increased by training in the euthyroid rats and by $\mathrm{T}_{3}$ treatment in the sedentary and trained rats. As it is shown in Fig. 1, plasma levels of $\mathrm{FT}_{3}$ increased, whereas $\mathrm{FT}_{4}$ levels decreased in hyperthyroid rats in comparison with respective euthyroid controls. Conversely, there were not differences in $\mathrm{FT}_{3}$ and $\mathrm{FT}_{4}$ levels between sedentary and trained animals.

\section{COX activity}

In liver homogenates, COX activity was increased by $\mathrm{T}_{3}$ administration in both sedentary and trained rats and was not modified by training in euthyroid and hyperthyroid animals. In liver mitochondria, COX activity was increased by $T_{3}$ treatment in sedentary and trained group and was significantly decreased by training in both thyroid states (Table 1).

The ratio between COX activities in homogenates and mitochondria provided a rough estimate of tissue content of 


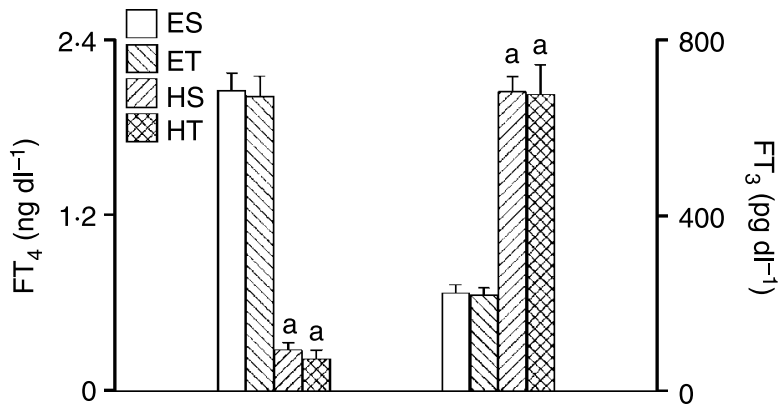

Figure 1 Serum thyroid hormone levels in euthyroid sedentary (ES), euthyroid trained (ET), hyperthyroid sedentary (HS), and hyperthyroid trained (HT) rats. Values are means \pm s.E.M. of eight different experiments. $\mathrm{FT}_{3}$ and $\mathrm{FT}_{4}$ are serum level of free tri-iodothyronine and thyroxine respectively. ${ }^{\text {a }}$ Significant versus euthyroid controls. The level of significance was chosen as $P<0 \cdot 05$.

mitochondrial proteins. Such a content was higher in hyperthyroid rats than in respective euthyroid controls and was increased by training in both thyroid states.

\section{$\mathrm{O}_{2}$ consumption}

The rates of $\mathrm{O}_{2}$ consumption by liver homogenates are reported in Fig. 2 (upper panel). The rates of succinatesupported $\mathrm{O}_{2}$ consumption were higher in hyperthyroid rats than in euthyroid controls during both State 4 and State 3. Respiration rates were increased by training only in hyperthyroid rats during State 4 . Respiratory control ratio ( $\mathrm{RCR}$ ) values, which were $4 \cdot 3 \pm 0 \cdot 2,4 \cdot 0 \pm 0 \cdot 3,4 \cdot 8 \pm 0 \cdot 2$, and $4 \cdot 6 \pm 0 \cdot 2$ for ES, ET, HS, and HT rats respectively, were not significantly $(P>0 \cdot 05)$ affected by $\mathrm{T}_{3}$ and training. The rates of pyruvate/malate-supported $\mathrm{O}_{2}$ consumption were higher in hyperthyroid than in euthyroid controls during State 4 and State 3. Furthermore, they were increased by training in

Table 1 Cytochrome oxidase activities and mitochondrial protein content in rat liver

\section{Cytochrome oxidase}

\begin{tabular}{|c|c|c|c|}
\hline & Homogenate & Mitochondria & $\begin{array}{l}\text { Mitochondrial } \\
\text { protein }\end{array}$ \\
\hline \multicolumn{4}{|l|}{ Group } \\
\hline ES & $69 \cdot 3 \pm 1 \cdot 3$ & $0.94 \pm 0.01$ & $72 \cdot 7 \pm 3 \cdot 3$ \\
\hline ET & $67 \cdot 5 \pm 0.5$ & $0.84 \pm 0.01^{+}$ & $80 \cdot 4 \pm 1 \cdot 9^{\dagger}$ \\
\hline $\mathrm{HS}$ & $113 \cdot 0 \pm 1 \cdot 6^{*}$ & $1 \cdot 19 \pm 0 \cdot 02 *$ & $95 \cdot 0 \pm 3 \cdot 0^{*}$ \\
\hline HT & $108 \cdot 5 \pm 2 \cdot 3 *$ & $0.99 \pm 0.02^{*,+}$ & $109 \cdot 5 \pm 1 \cdot 7^{*,+}$ \\
\hline
\end{tabular}

Values are means \pm S.E.M. For each value eight rats were used. Cytochrome oxidase activity (COX) is expressed in $\mu \mathrm{mol} \mathrm{O} / \mathrm{min}$ per milligram mitochondrial protein or $\mathrm{g}$ tissue. Mitochondrial protein is expressed as $\mathrm{mg}$ protein per g tissue. ES, euthyroid sedentary rats; ET, euthyroid trained rats; HS, hyperthyroid sedentary rats; HT, hyperthyroid trained rats. *Significant versus euthyroid controls. ${ }^{+}$Significant versus sedentary animals. Treatment $X$ training interaction significant for mitochondrial COX. The level of significance was chosen as $P<0 \cdot 05$.

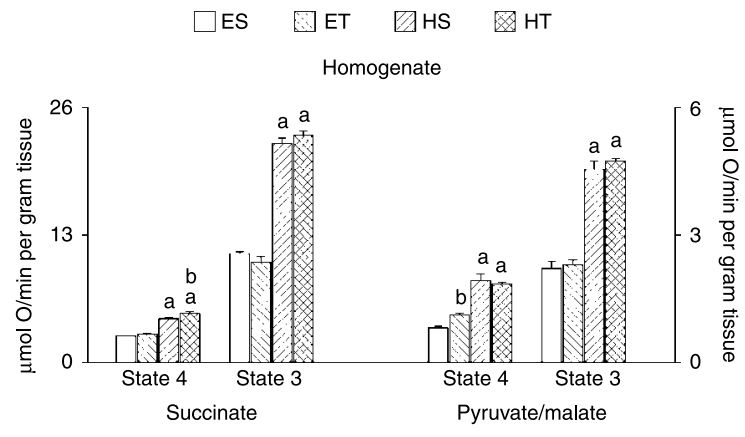

Mitochondria

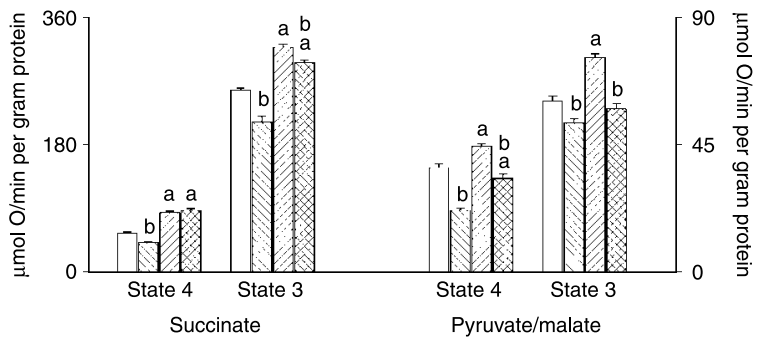

Figure 2 Rates of $\mathrm{O}_{2}$ consumption by rat liver homogenates (upper panel) and mitochondria (bottom panel) from euthyroid sedentary rats (ES); euthyroid trained rats (ET); hyperthyroid sedentary rats (HS); and hyperthyroid trained $(\mathrm{HT})$ rats. Values are means \pm S.E.M. of eight different experiments. Rates of $\mathrm{O}_{2}$ consumption were measured in the absence (State 4) and in the presence (State 3) of ADP with Complex II (succinate) and Complex I (pyruvate/malate) linked substrates. ${ }^{a}$ Significant versus euthyroid controls. ${ }^{b}$ Significant versus sedentary animals. Treatment $\times$ training interaction significant for State 4 homogenate respiration supported by pyruvate/malate, State 4 mitochondrial respiration supported by succinate, and State 3 mitochondrial respiration supported by succinate or pyruvate/malate. The level of significance was chosen as $P<0 \cdot 05$.

euthyroid rats during State 4 . RCR values, which were $2 \cdot 8 \pm$ $0 \cdot 1,2 \cdot 1 \pm 0 \cdot 1,2 \cdot 2 \pm 0 \cdot 1$, and $2 \cdot 6 \pm 0 \cdot 1$ for ES, ET, HS, and HT rats respectively, were significantly $(P<0 \cdot 05)$ increased by $\mathrm{T}_{3}$ in trained rats and decreased in sedentary ones, whereas they were decreased by training in the euthyroid rats and increased in the hyperthyroid ones.

The rates of $\mathrm{O}_{2}$ consumption by liver mitochondria are reported in Fig. 2 (bottom panel). The rates of succinatesupported $\mathrm{O}_{2}$ consumption were higher in hyperthyroid rats than in euthyroid controls during both State 4 and State 3. Respiration rates were reduced by training in euthyroid rats during State 4 and in both thyroid states during State 3. RCR values, which were $4 \cdot 7 \pm 0 \cdot 1,5 \cdot 1 \pm 0 \cdot 3,3 \cdot 8 \pm 0 \cdot 1$, and $3 \cdot 3 \pm 0 \cdot 1$ for ES, ET, HS, and HT rats respectively, were significantly $(P<0 \cdot 05)$ reduced by $\mathrm{T}_{3}$ in sedentary and trained rats.

The rates of pyruvate/malate-supported $\mathrm{O}_{2}$ consumption were increased by $T_{3}$ in sedentary and trained rats during State 4 and in sedentary rats during State 3. Furthermore, the rates were decreased by training in both thyroid states during State 4 and State 3. RCR values, which were $1 \cdot 7 \pm 0 \cdot 1,2 \cdot 3 \pm 0 \cdot 1,1 \cdot 7 \pm 0 \cdot 1$, and $1 \cdot 8 \pm 0 \cdot 1$ for ES, ET, HS, 

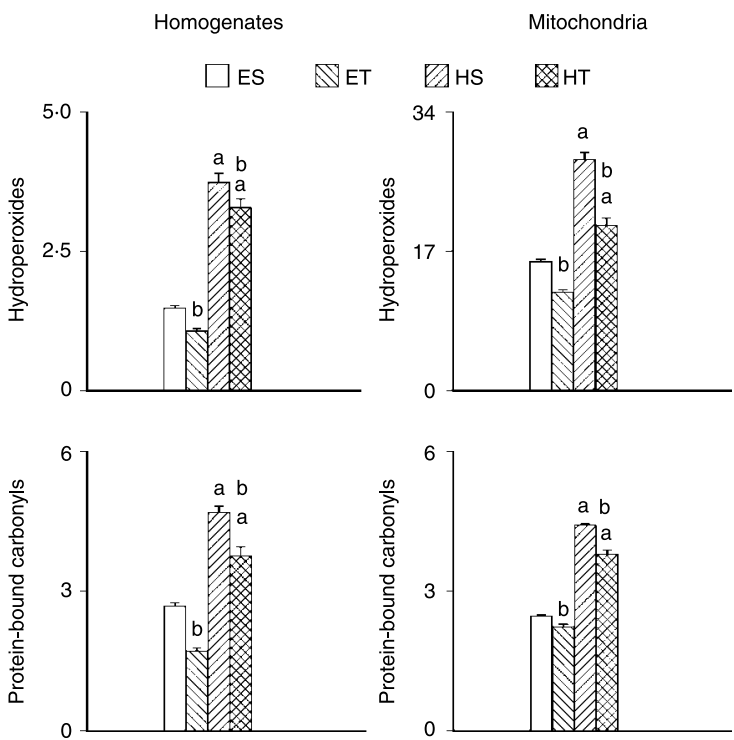

Figure 3 Oxidative damage in liver preparations from euthyroid sedentary (ES), euthyroid trained (ET), hyperthyroid sedentary (HS), and hyperthyroid trained (HT) rats. Values are means \pm s.E.M. of eight different experiments. Hydroperoxides (HPs) are expressed in nmol NADP $\mathrm{min} / \mathrm{g}$ tissue and $\mathrm{pmol}$ NADP $\mathrm{min} / \mathrm{mg}$ mitochondrial protein. Protein-bound carbonyls (CO) are expressed in nmol/mg protein. ${ }^{a}$ Significant versus euthyroid controls. ${ }^{\text {b }}$ Significant versus sedentary animals. Treatment $\times$ training interaction significant for mitochondrial HP and carbonyl levels. The level of significance was chosen as $P<0 \cdot 05$.

and HT rats respectively, were significantly $(P<0 \cdot 05)$ decreased by $T_{3}$ in trained rats and increased by training in euthyroid ones.

\section{Oxidative damage}

In liver homogenates and mitochondria, the levels of hydroperoxides and protein-bound carbonyls were significantly higher in hyperthyroid rats than in respective euthyroid controls. Furthermore, they were reduced by training in both thyroid states (Fig. 3).

\section{Antioxidants}

The activities of antioxidant enzymes and the levels of low molecular weight antioxidants in the liver homogenates are reported in Table 2. $\mathrm{T}_{3}$ treatment increased GPX activities in sedentary rats and decreased GR activities in both sedentary and trained animals. Training increased GPX activity in euthyroid but not in hyperthyroid rats and did not affect GR activities in both thyroid states. Changes in vitamin $\mathrm{E}$ were found only in HT liver, which exhibited levels lower than their euthyroid and untrained controls. CoQ9 and CoQ10 levels were not modified by $T_{3}$ administration or training. GSH levels were decreased by $\mathrm{T}_{3}$ treatment in trained and untrained rats, and were increased by training in both thyroid states.

\section{Response to oxidative challenge}

The luminescence response to changes of concentration of the homogenates (Fig. 4) was described by the equation $(E=a \cdot C / \exp (b \cdot C))$. The parameters $a$ and $b$, which determine the light emission maximum $\left(E_{\max }=a / e \cdot b\right)$, are dependent on the concentration of substances able to induce (iron or cuprum ligands) and inhibit (antioxidants) respectively the $\mathrm{H}_{2} \mathrm{O}_{2}$ induced luminescent reaction. Examination of the curves in Fig. 4 and data reported in Table 3 show that the emission maximum was increased by $T_{3}$ treatment in sedentary and trained rats, and was decreased by training in both thyroid states. The values of the parameters $a$ and $b$ indicate that the increase in emission peak induced by $\mathrm{T}_{3}$ treatment is due to lower $b$ values and higher $a$ values, while the decrease induced by training is mainly imputed to higher $b$ values.

\section{Mitochondrial $\mathrm{H}_{2} \mathrm{O}_{2}$ release and capacity to remove $\mathrm{H}_{2} \mathrm{O}_{2}$}

During both State 4 and State 3 respiration, the rates of succinate and pyruvate/malate supported $\mathrm{H}_{2} \mathrm{O}_{2}$ mitochondrial

Table 2 Antioxidants levels in rat liver homogenates. Values are means \pm s.E.M. For each value eight rats were used. Glutathione peroxidase activity $(G P X)$ is expressed in $\mu \mathrm{mol} N A D P H$ min/g tissue. Glutathione reductase (GR) is expressed in $\mu$ mol NADPH min/g tissue. Vitamin E (Vit E), coenzyme Q9 (CoQ9), and coenzyme Q10 (CoQ10) content is expressed in nmol/g tissue. Reduced glutathione (GSH) is expressed in $\mu \mathrm{mol} / \mathrm{g}$ tissue

\begin{tabular}{|c|c|c|c|}
\hline ES & ET & $\mathrm{HS}$ & HT \\
\hline $75 \cdot 7 \pm 1 \cdot 4$ & $85 \cdot 0 \pm 0 \cdot 8^{\dagger}$ & $85 \cdot 5 \pm 2 \cdot 8^{*}$ & $87 \cdot 6 \pm 2 \cdot 1$ \\
\hline $9 \cdot 0 \pm 0 \cdot 5$ & $9 \cdot 8 \pm 0 \cdot 3$ & $7 \cdot 7 \pm 0 \cdot 3 *$ & $8 \cdot 3 \pm 0 \cdot 1^{*}$ \\
\hline $49.94 \pm 1.63$ & $45 \cdot 44 \pm 0.69$ & $47 \cdot 31 \pm 0 \cdot 85$ & $35 \cdot 70 \pm 1 \cdot 50^{*,+}$ \\
\hline $76.98 \pm 1.63$ & $82 \cdot 27 \pm 3 \cdot 50$ & $82 \cdot 77 \pm 1 \cdot 26$ & $76 \cdot 72 \pm 1 \cdot 02$ \\
\hline $7 \cdot 44 \pm 0.22$ & $8 \cdot 59 \pm 0.31$ & $7.93 \pm 0.37$ & $7 \cdot 76 \pm 0 \cdot 62$ \\
\hline $4.79 \pm 0.09$ & $5 \cdot 49 \pm 0 \cdot 39^{+}$ & $2 \cdot 61 \pm 0.07 *$ & $3 \cdot 48 \pm 0.09^{*,+}$ \\
\hline
\end{tabular}

ES, euthyroid sedentary rats; ET, euthyroid trained rats; HS, hyperthyroid sedentary rats; HT, hyperthyroid trained rats. *Significant versus euthyroid controls. ${ }^{+}$Significant versus sedentary animals. Treatment $\times$training interaction significant for vitamin $E$ and CoQ9 content. The level of significance was chosen as $P<0 \cdot 05$. 


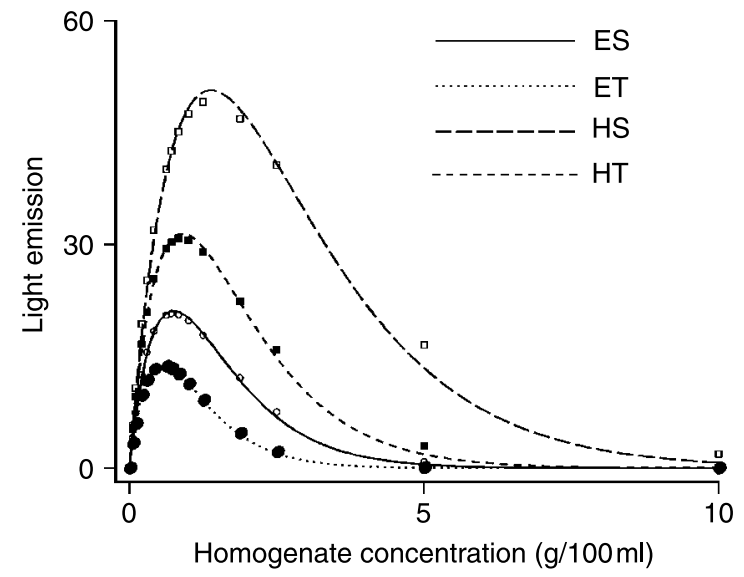

Figure 4 Response to in vitro oxidative challenge of liver homogenates from euthyroid sedentary (ES), euthyroid trained (ET), hyperthyroid sedentary (HS), and hyperthyroid trained (HT) rats. Tissue susceptibility to stress was evaluated by determining the variations, with concentration of homogenates, of light emission from a luminescent reaction. Emission values are given percentage of an arbitrary standard ( $44 \mathrm{ng} / \mathrm{ml}$ peroxidase). The curves were computed from experimental data by equation $E=a$. $C / \exp (b \cdot C)$.

release were increased by $T_{3}$ treatment in sedentary and trained rats, and were decreased by training in both thyroid states (Fig. 5).

The capacities to remove $\mathrm{H}_{2} \mathrm{O}_{2}$ were increased by $\mathrm{T}_{3}$ treatment $(P<0 \cdot 05)$ in trained and untrained rats and were decreased by training in both thyroid states $(P<0 \cdot 05)$. The values, expressed as equivalent concentration of desferroxamine (nmol/mg protein), were $3 \cdot 18 \pm 0 \cdot 09,2 \cdot 77 \pm 0 \cdot 05$, $4 \cdot 13 \pm 0 \cdot 10$, and $3 \cdot 45 \pm 0 \cdot 07$ for ES, ET, HS, and HT rats respectively.

\section{Effect of inhibitors on $\mathrm{H}_{2} \mathrm{O}_{2}$ release}

As shown in Table $4, \mathrm{~T}_{3}$ treatment increased the rate of mitochondrial succinate-supported $\mathrm{H}_{2} \mathrm{O}_{2}$ release, in the absence of rotenone, in both sedentary and trained rats, whereas training reduced it in both thyroid states. As expected, rotenone addition decreased the rates of $\mathrm{H}_{2} \mathrm{O}_{2}$ release in all groups, by stopping the release occurring at
Complex I, due to the reverse electron flow from coenzyme Q (Ernster \& Lee 1967). However, the rates were again increased by $\mathrm{T}_{3}$ and decreased by training. Analogous results were obtained after further addition of antimycin, which increased $\mathrm{H}_{2} \mathrm{O}_{2}$ release rates in all groups. Addition of antimycin or rotenone to pyruvate/malate supported mitochondria increased $\mathrm{H}_{2} \mathrm{O}_{2}$ release rates in all groups. However, whereas in the presence of antimycin, the significance of differences between groups was not modified, in the presence of rotenone the rates of $\mathrm{H}_{2} \mathrm{O}_{2}$ release were not different in sedentary and trained hyperthyroid rats.

\section{Mitochondrial swelling}

As shown by the absorbance changes in Fig. 6, the extent of swelling was increased by $\mathrm{T}_{3}$ treatment in $\mathrm{Ca}^{2+}$-loaded mitochondria from sedentary rats, but not in mitochondria from trained rats. Mitochondrial swelling was drastically reduced by CSA or EGTA (unreported results), pointing to the role played by the permeability transition pore. $\mathrm{Ca}^{2+}$ induced swelling was preceded by a rapid decrease in membrane potential, which was greater in preparations from sedentary hyperthyroid rats than in those from trained rats. No difference in $\mathrm{Ca}^{2+}$-induced mitochondrial swelling and $\Delta \Psi$ decrease were found in euthyroid preparations (Fig. 6).

\section{Discussion}

A first consideration, elicited from the results reported in this paper, concerns the effects on the liver oxidative metabolism capacity of $\mathrm{T}_{3}$ prolonged administration to sedentary and trained rats. The aerobic metabolic capacity of tissues can be evaluated measuring the in vitro COX activity, which is positively correlated to the maximal oxygen consumption (Simon \& Robin 1971). It has been reported that training does not modify COX activity and, therefore, the oxidative capacity of liver (Terblanche et al. 2001), which, conversely, increases in experimental (Venditti et al. 1999a, 2006) and functional (Venditti et al. 2004, 2006) hyperthyroidism. The present results confirm the above reports and indicate

Table 3 Parameters characterizing the response to oxidative stress of rat liver homogenates. Values are means \pm S.E.M. For each value eight rats were used. For explanation of symbols see text. The relation between light emission and homogenate concentration is described by the equation: $E=a \cdot C / \exp (b \cdot C) . E_{\max }=a / e \cdot b$

\section{Group}

\begin{tabular}{|c|c|c|c|}
\hline ES & ET & $\mathrm{HS}$ & $\mathrm{HT}$ \\
\hline $72 \cdot 8 \pm 5 \cdot 4$ & $70 \cdot 3 \pm 4 \cdot 2$ & $98 \cdot 7 \pm 3 \cdot 7^{*}$ & $90 \cdot 0 \pm 6 \cdot 5^{*}$ \\
\hline $1 \cdot 34 \pm 0.03$ & $1 \cdot 81 \pm 0 \cdot 12^{\dagger}$ & $0.75 \pm 0.08^{*}$ & $1 \cdot 03 \pm 0 \cdot 10^{*,+}$ \\
\hline $20 \cdot 0 \pm 1 \cdot 1$ & $14 \cdot 3 \pm 1 \cdot 5^{+}$ & $48 \cdot 4 \pm 2 \cdot 4^{*}$ & $32 \cdot 12 \pm 2 \cdot 1^{*,+}$ \\
\hline
\end{tabular}

ES, euthyroid sedentary rats; ET, euthyroid trained rats; HS, hyperthyroid sedentary rats; HT, hyperthyroid trained rats. *Significant versus euthyroid controls. ${ }^{+}$Significant versus sedentary animals. Treatment $\times$training interaction significant for $E_{\max }$. The level of significance was chosen as $P<0 \cdot 05$. 


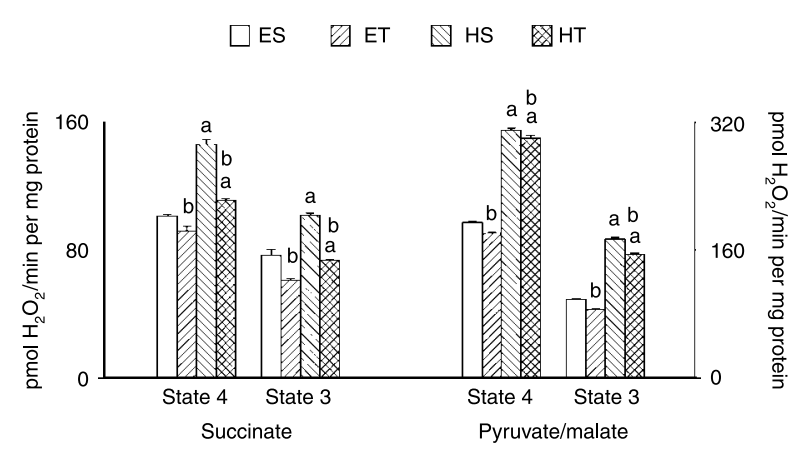

Figure 5 Rates of $\mathrm{H}_{2} \mathrm{O}_{2}$ release by liver mitochondria from euthyroid sedentary (ES), euthyroid trained (ET), hyperthyroid sedentary (HS), and hyperthyroid trained $(\mathrm{HT})$ rats. Values are means \pm s.E.M. of eight different experiments. Rates of $\mathrm{H}_{2} \mathrm{O}_{2}$ release were measured in the absence (State 4) and in the presence (State 3) of ADP with Complex II (succinate) and Complex I (pyruvate/malate) linked substrates. ${ }^{a}$ Significant versus euthyroid controls. ${ }^{b}$ Significant versus sedentary animals. Treatment $\times$ training interaction significant for $\mathrm{H}_{2} \mathrm{O}_{2}$ release sustained by succinate during State 4 and State 3 , and $\mathrm{H}_{2} \mathrm{O}_{2}$ release sustained by pyruvate/malate during State 3 . The level of significance was chosen as $P<0 \cdot 05$.

that $\mathrm{T}_{3}$ induces similar increases in liver oxidative capacity in sedentary and trained rats.

These increases were due, in both animal groups, to enhanced mitochondrial aerobic capacity and tissue content of mitochondrial proteins. However, the changes in aerobic capacity were greater in HS group, whereas those in protein content were greater in HT group. Our results also suggest that training does not increase liver aerobic capacity, because the proliferation of mitochondrial population it seems to induce is accompanied by a decrease in the aerobic capacity of the organelles.

The mitochondrial proliferation found in hyperthyroid liver can be attributed to the capacity of $\mathrm{T}_{3}$ to increase the expression of peroxisomal proliferator-activated receptor gamma co-activator (PGC)-1, a transcriptional coactivator that plays a pivotal role in mitochondrial biogenesis (Weitzel et al. 2001). On the other hand, catecholamines may be responsible for mitochondrial proliferation in the liver from trained rats. In fact, recent studies have shown i) an increased PGC-1 expression in muscle from swimming trained rats (Goto et al. 2000), ii) an increased plasma catecholamine level during single swimming sessions (Park et al. 2005) and an increased PGC-1 expression in murine muscle in response to exercise linked to $\beta$-adrenergic receptor activation (Miura et al. 2007).

Interestingly, the prolonged $\mathrm{T}_{3}$ administration and training elicited changes in the oxidative capacity of homogenates and mitochondria were reflected in the changes in succinate and pyruvate/malate sustained State 3 respiration of these preparations. This suggests that both treatments modify liver mitochondrial population without alter the ratios among the components of respiratory chain.

Some changes in State 4 respiration rate induced by training in mitochondria and homogenates remain to be understood. The increase in basal respiration rates represents a compensatory response to increased leak of protons back in the mitochondrial matrix. Thus, the increases induced by $\mathrm{T}_{3}$ are consistent with an enhanced basal proton conductance dependent on oxidative modifications of inner mitochondrial membrane lipids (Brand 2000). In this light, the respiration rates should have to decrease in mitochondrial preparations from trained rats, but this does not happen in succinatesupplemented mitochondria from HT rats. Moreover, although the changes found in homogenates can be explained by the increased tissue content in mitochondrial proteins, the pyruvate/malate-supported respiration rate measured in homogenates from ET rats appears to be out of proportion to the mitochondrial protein content.

There are a few studies concerning the chronic swimming effects on liver oxidative damage in euthyroid rats, which reported discrepant results (Venditti \& Di Meo 1996, 1997, Aydin et al. 2007), likely due to different training protocols. Conversely, there is full agreement about thyroid hormone

Table 4 Effects of inhibitors specific for different segments of the respiratory chain on rates of $\mathrm{H}_{2} \mathrm{O}_{2}$ release by rat liver mitochondria. Values are means \pm S.E.M. For each value eight rats were used. Mitochondrial $\mathrm{H}_{2} \mathrm{O}_{2}$ release rate is expressed in $\mathrm{pmol} \mathrm{min}^{-1} \mathrm{mg}^{-1} \mathrm{protein}$

\section{Group}

\begin{tabular}{|c|c|c|c|}
\hline ES & ET & $\mathrm{HS}$ & HT \\
\hline $115 \cdot 3 \pm 1 \cdot 0$ & $101 \cdot 2 \pm 0 \cdot 8^{\dagger}$ & $179 \cdot 0 \pm 2 \cdot 3^{*}$ & $132 \cdot 6 \pm 0 \cdot 6^{*,+}$ \\
\hline $101 \cdot 4 \pm 1 \cdot 1^{\ddagger}$ & $92 \cdot 0 \pm 2 \cdot 9^{\dagger, \neq}$ & $146 \cdot 5 \pm 2 \cdot 4^{*, \neq}$ & $111 \cdot 4 \pm 0 \cdot 8^{*,+, \neq}$ \\
\hline $803 \cdot 8 \pm 9 \cdot 8^{\neq}$ & $718 \cdot 3 \pm 1 \cdot 8^{\dagger, \neq}$ & $919 \pm 14 \cdot 8^{*, \neq}$ & $830 \cdot 7 \pm 3 \cdot 4^{*,+, \neq}$ \\
\hline $194 \cdot 7 \pm 1 \cdot 5$ & $181 \cdot 1 \pm 1 \cdot 1^{\dagger}$ & $310 \cdot 4 \pm 2 \cdot 7^{*}$ & $300 \cdot 2 \pm 4 \cdot 3^{*,+}$ \\
\hline $992 \cdot 9 \pm 4 \cdot 2^{\ddagger}$ & $924 \cdot 4 \pm 2 \cdot 2^{+, \neq}$ & $1036 \cdot 8 \pm 11 \cdot 4^{*, \neq}$ & $1020 \cdot 6 \pm 17 \cdot 3^{*,+, \neq}$ \\
\hline $194 \cdot 6 \pm 2 \cdot 5$ & $182 \cdot 0 \pm 1 \cdot 2^{+}$ & $310 \cdot 9 \pm 2 \cdot 6^{*}$ & $300 \cdot 5 \pm 3 \cdot 4^{*+}$ \\
\hline $227 \cdot 6 \pm 2 \cdot 6^{\ddagger}$ & $214 \cdot 8 \pm 1 \cdot 2^{+, \neq}$ & $332 \cdot 8 \pm 2 \cdot 4^{*, \neq}$ & $329 \cdot 5 \pm 2 \cdot 5^{*, \neq}$ \\
\hline
\end{tabular}

\author{
Substrate \\ Succinate (Succ) \\ Succ + Rot \\ Succ + Rot + AA \\ Pyruvate/Malate (Pyr/Mal) \\ Pyr/Mal+AA \\ Pyr/Mal \\ Pyr/Mal+ Rot
}

ES, euthyroid sedentary rats; ET, euthyroid trained rats; HS, hyperthyroid sedentary rats; HT, hyperthyroid trained rats. *Significant versus euthyroid controls.
${ }^{+}$Significant versus sedentary animals; ${ }^{*}$ significant effect of the last inhibitor added versus mitochondria under same conditions without that inhibitor. Treatment $\times$
training interaction significant for $\mathrm{H}_{2} \mathrm{O}_{2}$ release in the presence of succinate, succinate plus rotenone, pyruvate/malate plus antimycin or rotenone. The level of
significance was chosen as $P<0 \cdot 05$.

www.endocrinology-journals.org 

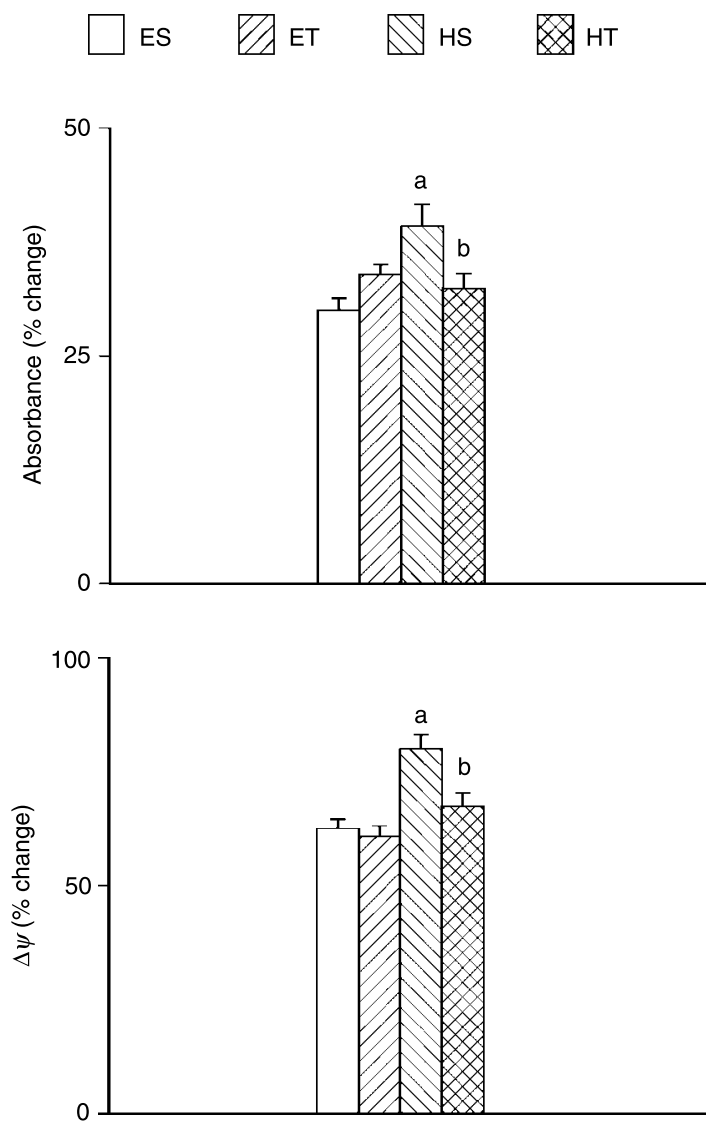

Figure $6 \mathrm{Ca}^{2+}$-induced swelling (upper panel) and membrane potential dissipation (lower panel) of liver mitochondria from euthyroid sedentary (ES), euthyroid trained (ET), hyperthyroid sedentary (HS), and hyperthyroid trained (HT) rats. Swelling, monitored as decrease in the absorbance at $540 \mathrm{~nm}$, is expressed as percentage of the initial value before $\mathrm{Ca}^{2+}$ addition. Membrane potential $(\Delta \Psi)$, estimated through fluorescence changes of safranine, was calculated using a suitable calibration curve. Its decrease is expressed as percentage of the initial value before $\mathrm{Ca}^{2+}$ addition. Values are means \pm S.E.M. of eight different experiments. The initial absorbance values were $0 \cdot 85 \pm 0 \cdot 04,0.90 \pm 0.07$, $0 \cdot 86 \pm 0.05$, and $0 \cdot 83 \pm 0.05$ for $\mathrm{ES}, \mathrm{ET}, \mathrm{HS}$, and $\mathrm{HT}$ preparations respectively. Initial values of $\Delta \Psi$ were $149 \cdot 1 \pm 11 \cdot 5,152 \cdot 7 \pm 10 \cdot 4$, $140 \cdot 6 \pm 9 \cdot 7$, and $147 \cdot 0 \pm 8 \cdot 9$ for ES, ET, HS, and HT preparations respectively. ${ }^{a}$ Significant versus euthyroid controls. ${ }^{b}$ Significant versus sedentary animals. Treatment $X$ training interaction significant for swelling and membrane potential. The level of significance was chosen as $P<0 \cdot 05$.

promotion of liver oxidative damage (Videla 2000, Venditti \& Di Meo 2006). The present results show that moderate training reduces lipid and protein oxidation in euhyroid animals and attenuates its increase associated with $\mathrm{T}_{3}$ administration, suggesting that training exerts a strong protective effect against $\mathrm{T}_{3}$-induced oxidative stress.

Oxidative stress results from a disturbance of the normal cell balance between production of ROS and the capacity to neutralize their action. Thus, in order to understand the mechanisms underlying the differential effects of $T_{3}$ on liver oxidative damage in sedentary and trained rats, we examined changes in liver capacity to generate and neutralize free radicals.

In previous reports, we showed that the total antioxidant capacity of rat liver is increased by training (Venditti \& Di Meo 1996, 1997) and decreased by $\mathrm{T}_{3}$ treatment (Venditti et al. 1997, 1999a). The determination of total antioxidant capacity on tissue preparations presents several limits. On the other hand, due to the complexity of the antioxidant defense systems, investigations on tissue antioxidant status based on the determination of single antioxidant compounds or enzymes often does not offer a coherent pattern. This also happens for the data here reported, concerning some components of the antioxidant defense system, which do not allow to establish whether the effectiveness of such system is differently modified by $\mathrm{T}_{3}$ treatment in sedentary and trained rats. Indeed, the levels of some antioxidants are not modified by training in hyperthyroid rats, whereas those of vitamin E and GSH undergo opposite changes, likely because the different degree of GSH depletion is not the cause, but the consequence of the different levels of oxidative stress in the two rat groups. However, some information was obtained by examining the liver sensitivity to oxidative processes by measuring the levels of light emission resulting from in vitro exposure to $\mathrm{H}_{2} \mathrm{O}_{2}$ of liver homogenates. As the emission maximum indicates the susceptibility of the preparations to oxidative challenge (Venditti et al. 1999c), our results reveal that such a susceptibility is reduced by training, but in greater measure in $\mathrm{T}_{3}$-treated animals. Also, the results indicate that the lower susceptibility to oxidants found in trained groups is mainly due to a higher antioxidant capacity. Thus, there is indirect evidence that a greater effectiveness of the antioxidant defense system contributes to the lower degree of oxidative damage induced by $\mathrm{T}_{3}$ in the liver from trained rats.

More clear information has been obtained on ROS generation contribution to the different extent of oxidative damage found in sedentary and trained rats. ROS are produced in several cellular sites, but mitochondria have long been recognized as the major source of free radicals (Liu et al. 2002). The enhancement in mitochondrial protein content of hyperthyroid livers should lead to increased ROS flow from mitochondria to cytoplasm. However, it is apparent that training protects the hepatic tissue against oxidative damage by inducing adaptive modifications that prevent the elevated mitochondrial $\mathrm{H}_{2} \mathrm{O}_{2}$ efflux. Indeed, training limits the $\mathrm{T}_{3}$-induced increase in $\mathrm{H}_{2} \mathrm{O}_{2}$ mitochondrial release rates. The effect concerns mainly the $\mathrm{H}_{2} \mathrm{O}_{2}$ release during State 4 respiration sustained by Complex II-linked substrate, so that in the trained group the rate of $\mathrm{H}_{2} \mathrm{O}_{2}$ release per $\mathrm{g}$ of tissue is $87 \%$ of that found in sedentary group. A training-induced reduction of succinate-supported ROS release occurs also in euthyroid rats. However, such reduction is small and is able only to compensate the increase in mitochondrial protein content.

The observation that the mitochondrial capacity to remove $\mathrm{H}_{2} \mathrm{O}_{2}$ is higher in hyperthyroid than in euthyroid groups and in sedentary than in trained groups indicates that the differences in 
$\mathrm{H}_{2} \mathrm{O}_{2}$ release reflect differences in the production of the $\mathrm{H}_{2} \mathrm{O}_{2}$ precursor, the superoxide radical $\left(\mathrm{O}_{2}^{-}\right)$. Such a production, in turn, depends on concentration and reduction degree of the autoxidizable electron carriers located at Complex I and Complex III of the respiratory chain. Information on the relative contribution of autoxidizable carriers to the $\mathrm{O}_{2}^{-}$ generation in sedentary and trained rats can be obtained by analyzing the effects of respiratory inhibitors and substrates on $\mathrm{H}_{2} \mathrm{O}_{2}$ release. This analysis indicates that the increase in $\mathrm{H}_{2} \mathrm{O}_{2}$ release shown in hyperthyroid rats is due to an increased concentration of both autoxidizable electron carriers. This idea is supported by previous reports showing that hyperthyroidism increases the content of several components of respiratory chain in liver mitochondria (Jacovcic et al. 1978, Horrum et al. 1985, 1986). However, our results are not able to show the presence within the respiratory chain of a main site responsible for the enhanced $\mathrm{H}_{2} \mathrm{O}_{2}$ production. On the other hand, it is possible, as previously suggested (Venditti et al. 2003), that mitochondria undergo a generalized thyroid hormone-linked change in electron carrier content.

Conversely, it is apparent that the prolonged $\mathrm{T}_{3}$ administration to trained rats induces a smaller increase in the mitochondrial content of the ROS generator located at Complex III. Indeed, in the presence of rotenone, succinatesupported mitochondrial $\mathrm{H}_{2} \mathrm{O}_{2}$ release is lower in trained group than in the sedentary one, whereas the release supported by pyruvate/malate is not significantly different in the two groups. Further support comes from the results obtained in the presence of antimycin A, which makes ROS production dependent only on the concentration of autoxidizable carriers. Such results show that $\mathrm{H}_{2} \mathrm{O}_{2}$ release is lower in the trained group when it depends on the Complex III generator, i.e. in the presence of succinate, whereas there are not differences between the groups when it depends on the Complex I and III generators, i.e., in the presence of pyruvate/malate. Finally, when pyruvate/malatesupplemented mitochondria are treated with rotenone, which makes $\mathrm{H}_{2} \mathrm{O}_{2}$ release dependent only on the concentration of the Complex I generator, such release is not significantly different in the two hyperthyroid groups. We also observed that, in the presence of rotenone, pyruvate/malate-sustained $\mathrm{H}_{2} \mathrm{O}_{2}$ release was lower in trained than in sedentary euthyroid rats. However, to date we are not able to offer a convincing explanation for this different effect of training on autoxidizable carrier of Complex I in euthyroid and hyperthyroid rats.

The $T_{3}$ and training-dependent changes in ROS generation have important implications for the function and even the viability of mitochondria, because these organelles are the main target of the ROS they produce. It is known that hyperthyroidism leads to an increase in total liver $\mathrm{Ca}^{2+}$ concentration (Hummerich \& Soboll 1989). In the presence of this ion, oxidative alterations of protein thiols of the mitochondrial inner membrane promote a membrane permeabilization referred to as mitochondrial permeability transition (Zoratti \& Szabo 1995), which leads to mitochondrial swelling. Our results show that mitochondrial susceptibility to $\mathrm{Ca}^{2+}$-induced swelling is significantly lower in trained than in sedentary hyperthyroid rats. This observation is consistent with the failure of $T_{3}$ to induce similar levels of oxidative stress and ROS production in mitochondria from sedentary and trained animals.

In conclusion, this work supplies strong indication that training limits the oxidative stress brought out in the hepatic tissue by prolonged thyroid hormone treatment, reducing mitochondrial ROS production and preserving the antioxidant system effectiveness. Because it has been recently shown that functional recovery from ischemia reperfusion of hyperthyroid hearts is increased by training (Venditti et al. 2008), it is apparent that, together with antioxidant integration, properly graded physical activity can protect hyperthyroid tissues against the oxidative damage-linked dysfunctions.

\section{Acknowledgements}

This work was supported by grants from Italian Ministry of University and Scientific and Technological Research. The authors declare that there is no conflict of interest that would prejudice the impartiality of this scientific work.

\section{References}

Åkerman KEO \& Wikström MKF 1976 Safranine as a probe of the mitochondrial membrane potential. FEBS Letters 68 191-197.

Aydin C, Ince E, Koparan S, Cangul IT, Naziroglu M \& Ak F 2007 Protective effects of long term dietary restriction on swimming exercise-induced oxidative stress in the liver, heart and kidney of rat. Cell Biochemistry and Function 25 129-137.

Barré H, Bailly L \& Rouanet JL 1987 Increased oxidative capacity in skeletal muscles from acclimated ducklings: a comparison with rats. Comparative Biochemistry and Physiology 88B 519-522.

Brady PS, Brady LJ \& Ulrey DE 1979 Selenium, vitamin E, and the response to swimming stress in the rat. Journal of Nutrition 109 1103-1109.

Brand MD 2000 Uncoupling to survive? The role of mitochondrial inefficiency in ageing Experimental Gerontology 35 811-820.

Brand MD \& Murphy MP 1987 Control of electron flux through the respiratory chain in mitochondria and cells. Biological Reviews 62 141-193.

Carlberg I \& Mannervik B 1985 Glutathione reductase. Methods in Enzymology 113 484-499.

Ernster L \& Lee C-P 1967 Energy-linked reduction of $\mathrm{NAD}^{+}$by succinate. Methods in Enzymology 10 729-738.

Fernández V \& Videla LA 1993 Influence of hyperthyroidism on superoxide radical and hydrogen peroxide production by rat liver submitochondrial particles. Free Radical Research Communications 18 329-335.

Fernández V, Castillo I, Tapia G, Romanque P, Uribe-Echevarría S, Uribe M, Cartier-Ugarte D, Santander G, Vial MT \& Videla LA 2007 Thyroid hormone preconditioning: protection against ischemia-reperfusion liver injury in the rat. Hepatology 45 170-177.

Flohé L \& Günzler WA 1984 Glutathione peroxidase. Methods in Enzymology 105 115-121.

Gornall AG, Bardawill CJ \& David MM 1949 Determination of serum proteins by means of the biuret reaction. Journal of Biological Chemistry 177 751-766.

Goto M, Terada S, Kato M, Katoh M, Yokozeki T, Tabata I \& Shimokawa T 2000 cDNA Cloning and mRNA analysis of PGC-1 in epitrochlearis muscle in swimming-exercised rats. Biochemical and Biophysical Research Communications 274 350-354.

Griffith OW 1980 Determination of glutathione disulphide using glutathione reductase and 2-vinylpyridine. Analytical Biochemistry 106 207-212. 
Heath RL \& Tappel AL 1976 A new sensitive assay for the measurement of hydroperoxides. Analytical Biochemistry 76 184-191.

Horrum MA, Tobin RB \& Ecklund RE 1985 Thyroxine-induced changes in rat liver mitochondrial cytochromes. Molecular and Cellular Endocrinology 41 163-169.

Horrum MA, Tobin RB \& Ecklund RE 1986 Thyroxine-induced changes in rat liver mitochondrial ubiquinone. Biochemical and Biophysical Research Communications 138 381-386.

Hummerich H \& Soboll S 1989 Rapid stimulation of calcium uptake into rat liver by tri-iodothyronine. Biochemical Journal 258 363-367.

Hyslop PA \& Sklar LA 1984 A quantitative fluorimetric assay for the determination of oxidant production by polymorphonuclear leukocytes: its use in the simultaneous fluorimetric assay of cellular activation processes. Analytical Biochemistry 141 280-286.

Jacovcic S, Swift HH, Gross NJ \& Rabinowitz M 1978 Biochemical and stereological analysis of rat liver mitochondria in different thyroid states. Journal of Cell Biology 77 887-901.

Lang JK, Gohil K \& Packer L 1986 Simultaneous determination of tocopherols, ubiquinols, and ubiquinones in blood, plasma, tissue homogenates, and subcellular fractions. Analytical Biochemistry 157 106-116.

Liu Y, Fiskum G \& Schubert D 2002 Generation of reactive oxygen species by the mitochondrial electron transport chain. Journal of Neurochemistry 80 780-787.

Miura S, Kawanaka K, Kai Y, Tamura M, Goto M, Shiuchi T, Minokoshi Y \& Ezaki O 2007 An increase in murine skeletal muscle peroxisome proliferator-activated receptor-gamma coactivator-1alpha (PGC-1alpha) mRNA in response to exercise is mediated by beta-adrenergic receptor activation. Endocrinology 148 3441-3448.

Mohamadin AM, Hammad LN, El-Bab MF \& Abdel Gawad HS 2007 Attenuation of oxidative stress in plasma and tissues of rats with experimentally induced hyperthyroidism by caffeic acid phenylethyl ester. Basic Clinical Pharmacology and Toxicology 100 84-90.

Palmer G, Horgan DJ, Tisdale H, Singer TP \& Beinert H 1968 Studies on the respiratory chain-linked reduced nicotinamide adenine dinucleotide dehydrogenase. XIV. Location of the sites of inhibition of rotenone, barbiturates, and piericidin by means of electron paramagnetic resonance spectroscopy. Journal of Biological Chemistry 243 844-847.

Park E, Chan O, Li Q, Kiraly M, Matthewa SG, Vranic M \& Riddell MC 2005 Changes in basal hypothalamo-pituitary-adrenal activity during exercise training are centrally mediated. American Journal of Physiology 289 R1360-R1371.

Reznick AZ \& Packer L 1994 Oxidative damage to proteins: spectrophotometric method for carbonyl assay. Methods in Enzymology 233 357-363.

Schild L, Reinheckel T, Wiswedel I \& Augustin W 1997 Short-term impairment of energy production in isolated rat liver mitochondria by hypoxia/reoxygenation: involvement of oxidative protein modification. Biochemical Journal 328 205-210.

Schwartz HL \& Oppenheimer JH 1978 Physiologic and biochemical actions of thyroid hormone. Pharmacology and Therapeutics 3 349-376.

Servais S, Couturier K, Koubi H, Rouanet JL, Desplanches D, Sornay-Mayet $\mathrm{MH}$, Sempore B, Lavoie JM \& Favier R 2003 Effect of voluntary exercise on $\mathrm{H}_{2} \mathrm{O}_{2}$ release by subsarcolemmal and intermyofibrillar mitochondria. Free Radical Biology and Medicine 35 24-32.

Simon LM \& Robin ED 1971 Relationship of cytochrome oxidase activity to vertebrate total and organ oxygen consumption. International Journal of Biochemistry 2 560-573.

Terblanche SE, Gohil K, Packer L, Henderson GA \& Brooks GA 2001 The effects of endurance training and exhaustive exercise on mitochondrial enzymes in tissues of the rat (Rattus norvegicus). Comparative Biochemistry and Physiology 128A 889-896.

Troncoso P, Smok G \& Videla LA 1997 Potentiation of ischemia-reperfusion liver injury by hyperthyroidism in the rat. Free Radical Biology and Medicine 23 19-25.
Turrens JF, Alexandre A \& Lehninger AL 1985 Ubisemiquinone is the electron donor for superoxide formation by complex III of heart mitochondria. Archives of Biochemistry and Biophysics $237408-414$.

Venditti P \& Di Meo S 1996 Antioxidants, tissue damage, and endurance in trained and untrained young male rats. Archives of Biochemistry and Biophysics $33163-68$.

Venditti P \& Di Meo S 1997 Effect of training on antioxidant capacity, tissue damage and endurance of adult male rats. International Journal of Sports Medicine 18 497-502.

Venditti P \& Di Meo S 2006 Thyroid hormone-induced oxidative stress. Cellular and Molecular Life Sciences 63 414-434.

Venditti P, Balestrieri M, Di Meo S \& De Leo T 1997 Effect of thyroid state on lipid peroxidation, antioxidant defences, and susceptibility to oxidative stress in rat tissues. Journal of Endocrinology 155 151-157.

Venditti P, Daniele MC, Masullo P \& Di Meo S 1999a Antioxidant-sensitive triiodothyronine effects on characteristics of rat liver mitochondrial population. Cellular Physiology and Biochemistry 9 38-52.

Venditti P, Masullo P \& Di Meo S $1999 b$ Effect of training on $\mathrm{H}_{2} \mathrm{O}_{2}$ release by mitochondria from rat skeletal muscle. Archives of Biochemistry and Biophysics 372 315-320.

Venditti P, De Leo T \& Di Meo S 1999c Determination of tissue susceptibility to oxidative stress by enhanced luminescence technique. Methods in Enzymology 300 245-252.

Venditti P, Masullo P \& Di Meo S 2001 Hemoproteins affect $\mathrm{H}_{2} \mathrm{O}_{2}$ removal from rat tissues. International Journal of Biochemistry and Cell Biology 33 293-301.

Venditti P, De Rosa R \& Di Meo S 2003 Effect of thyroid state on $\mathrm{H}_{2} \mathrm{O}_{2}$ production by rat liver mitochondria. Molecular and Cellular Endocrinology 205 185-192.

Venditti P, De Rosa R, Portero-Otin M, Pamplona R \& Di Meo S 2004 Cold-induced hyperthyroidism produces oxidative damage in rat tissues and increases susceptibility to oxidants. International Journal of Biochemistry and Cell Biology 36 1319-1331.

Venditti P, Pamplona R, Ayala V, De Rosa R, Caldarone G \& Di Meo S 2006 Differential effects of experimental and cold-induced hyperthyroidism on factors inducing rat liver oxidative damage. Journal of Experimental Biology 209 817-825.

Venditti P, Bari A, Di Stefano L, Agnisola C \& Di Meo S 2008 Effect of $T_{3}$ treatment on the response to ischemia-reperfusion of heart preparations from sedentary and trained rats. Pflugers Archiv: European Journal of Physiology 455 667-676.

Videla LA 2000 Energy metabolism, thyroid calorigenesis, and oxidative stress: functional and cytotoxic consequences. Redox Report 5 265-275.

Videla LA, Smok G, Troncoso P, Simon KA, Junqueira VBC \& Fernández V 1995 Influence of hyperthyroidism on lindane-induced hepatoxicity in the rat. Biochemical Pharmacology 50 1557-1565.

Weitzel JM, Radtke C \& Seitz HJ 2001 Two thyroid hormone-mediated gene expression patterns in vivo identified by cDNA expression. Nucleic Acids Research 29 5148-5155.

Zoratti M \& Szabo I 1995 The mitochondrial permeability transition. Biochimica et Biophysica Acta 1241 139-176.

\section{Received in final form 14 December 2007 \\ Accepted 7 January 2008 \\ Made available online as an Accepted Preprint \\ 7 January 2008}

